\title{
Radical carbonylations using a continuous microflow system
}

\author{
Takahide Fukuyama, Md. Taifur Rahman, Naoya Kamata and Ilhyong Ryu*
}

\section{Preliminary Communication}

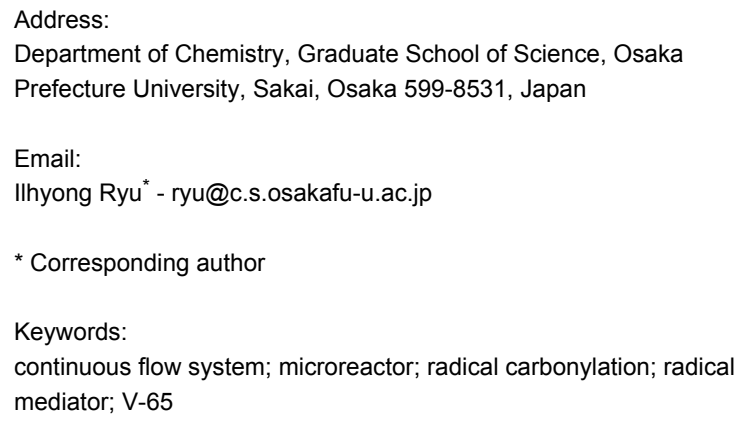

\author{
Beilstein Journal of Organic Chemistry 2009, 5, No. 34 \\ doi:10.3762/bjoc. 5.34 \\ Received: 14 April 2009 \\ Accepted: 02 July 2009 \\ Published: 13 July 2009 \\ Guest Editor: A. Kirschning \\ (C) 2009 Fukuyama et al; licensee Beilstein-Institut. \\ License and terms: see end of document.
}

\begin{abstract}
Radical-based carbonylation reactions of alkyl halides were conducted in a microflow reactor under pressurized carbon monoxide gas. Good to excellent yields of carbonylated products were obtained via radical formylation, carbonylative cyclization and threecomponent coupling reactions, using tributyltin hydride or TTMSS as a radical mediator.
\end{abstract}

\section{Introduction}

Placing a reaction mixture fluid inside a microstructured channel network helps gain a high surface area to volume ratio that in turn ensures rapid heat and mass transfer [1-3]. Precise control of reaction temperature and residence time, excellent mixing properties for reactants/reagents as well as a flow nature of the microreaction system, often result in higher conversion, greater yields, superior product selectivity and safety. In recent years, the potential of this new technology for organic synthesis have been recognized and many applications have been demonstrated by our group [4-6] as well as others [7-11].

In our recent report, we demonstrated that excellent thermal efficiency of the microflow system would lead to effective execution of tin hydride and TTMSS (tris(trimethylsilyl)silane)mediated radical reduction and cyclization reactions [12]. The
Seeberger group reported reduction and hydrosilylation using TTMSS in a microflow system [13]. In our study, we found that the combination of a rapidly decomposing radical initiator with a microreaction device allowed the reactions to be completed in a very short period of time giving good yields of the desired products. Carbon monoxide is an important feedstock and our group has actively pursued carbonylation reactions [14-17]. Thermally induced radical carbonylations using tin hydride usually require pressurized $\mathrm{CO}$ conditions to ensure that the concentration of $\mathrm{CO}$ around the radical centers is high enough to compete with the premature quenching by tin hydride (Scheme 1). Encouraged by our previous successes with both radical reactions [12] and metal-catalyzed carbonylation reactions using microflow devices [18-20], we decided to examine a continuous microreaction system for radical carbonylation reac- 


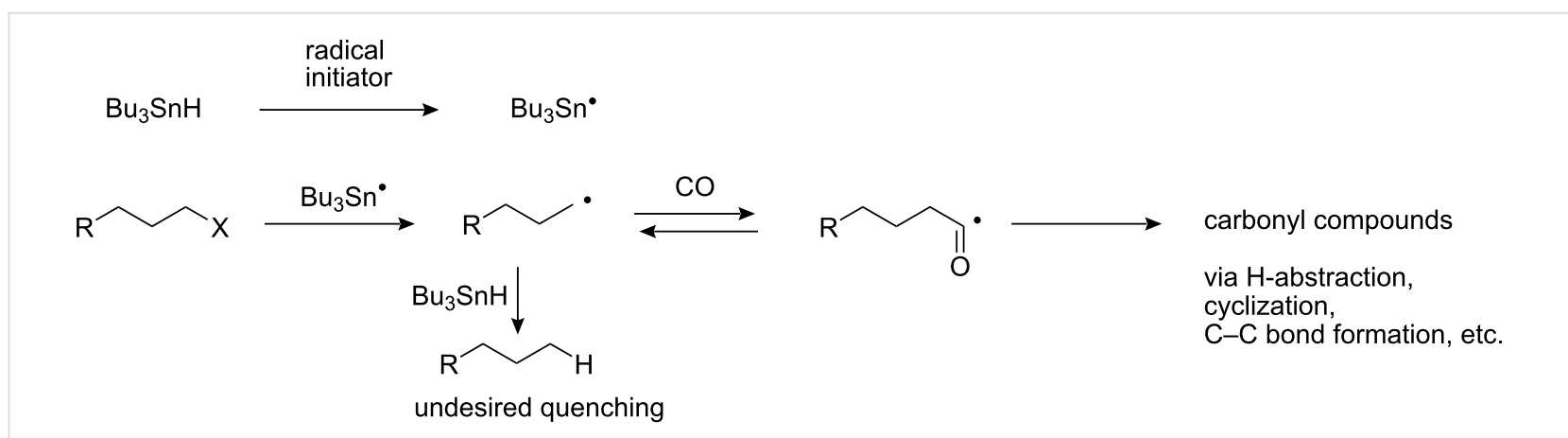

Scheme 1: Tin-mediated radical carbonylation and the competing reduction.

tions, for which we typically used stainless-steel autoclaves as the reactor in batch systems.

\section{Results and Discussion}

The microflow system we employed was simple, yet robust enough to withstand high CO pressures (ca. $80 \mathrm{~atm}$ ) (Figure 1). A metered stream of $\mathrm{CO}$ gas was fed in a controlled manner into the system and was mixed with the toluene solution containing a radical mediator, a radical initiator and a substrate in a T-shaped micromixer (stainless steel, internal diameter: $1000 \mu \mathrm{m}$ ). This biphasic (gas-liquid) mixture was then guided through a stainless steel tubular reactor (internal diameter: 1000 $\mu \mathrm{m})$, acting as the residence time unit (RTU), under heated conditions using an oil bath. A back pressure control valve was connected at the end of the RTU to regulate and maintain the pressure of the reactor system. Reaction time was adjusted via the flow rates of $\mathrm{CO}$ and the liquid.

Using the microflow system depicted by Figure 1, we carried out the radical formylation of 1-bromododecane (1) with $\mathrm{CO}$ in the presence of tributyltin hydride (bath temp. $80{ }^{\circ} \mathrm{C}$ ) [21]. However, we encountered incomplete conversion of the starting bromide when we used AIBN (2,2'-azobisisobutyronitrile) as a radical initiator. This was attributed to the rather slow decomposition rate of the AIBN (half-life time: 90 min at $85^{\circ} \mathrm{C}$ ) in light of the time frame employed for the microflow reaction (residence time, $12 \mathrm{~min}$ ). When we switched AIBN to a more rapidly decomposing V-65 (2,2'-azobis(2,4-dimethylvaleronitrile), half-life time: $12 \mathrm{~min}$ at $\left.80{ }^{\circ} \mathrm{C}\right), 100 \%$ conversion was attained to give tridecanal (2) in a $77 \%$ yield (Table 1, entry 1 ). Microflow carbonylation of bromocyclohexane (3) and 1-bromoadamantane (5) also worked well to furnish the corresponding aldehydes $\mathbf{4}$ and $\mathbf{6}$ in good yields (entries 2 and 3). The judicious choice of a radical initiator is important for high conversion in a short reaction time for carbonylation reactions, which is in accordance with our previous experience with microflow radical reduction and cyclization of organic halides using tributyltin hydride [12].

Tin-mediated radical carbonylation has a wide range of applications including carbonylative cyclization and multi-component coupling reactions. In this regard, we again chose stannylcarbonylation using 1,6-azaenyne 7 as a model for cyclization [22, 23]. Using a similar microflow system but with an extended reaction time, we were able to obtain the desired six-membered ring lactam 8 in good yield (entry 4). Using a similar micro-

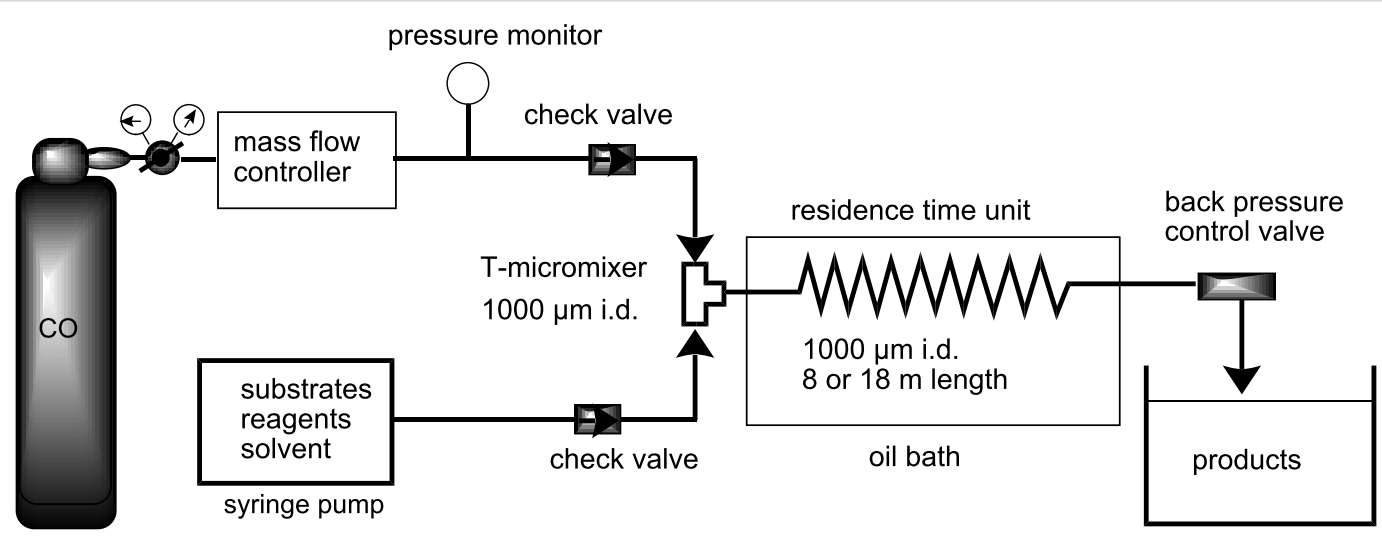

Figure 1: Microflow system available for radical carbonylation using pressurized $\mathrm{CO}$. 
Table 1: Radical carbonylation in a microflow system. ${ }^{\text {a }}$

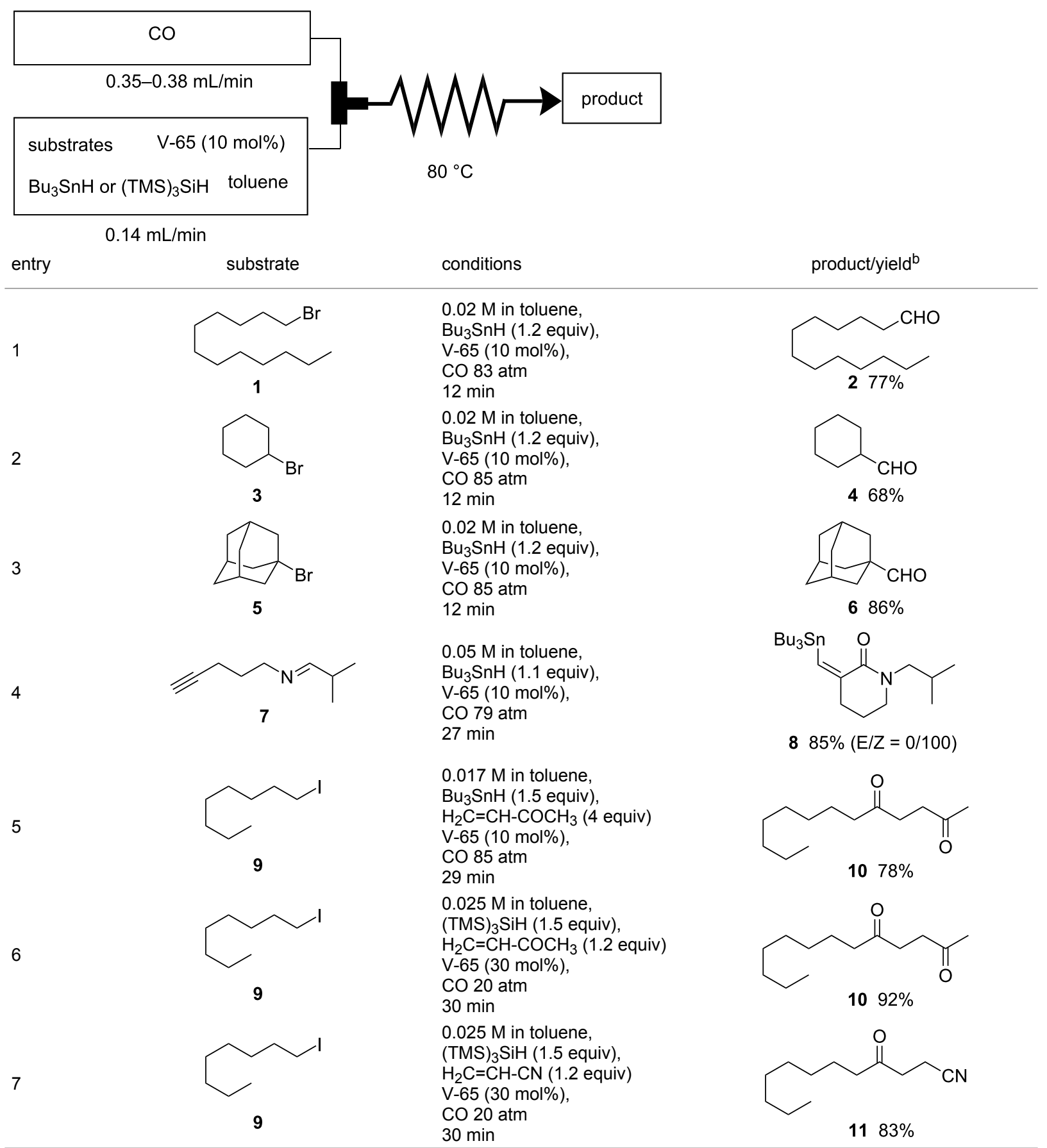

aConditions: substrate ( $1 \mathrm{mmol}, 0.017-0.05 \mathrm{M}$ in toluene), Bu 3 SnH or TTMSS (1.1-1.5 equiv), V-65 (10-30 mol\%), CO (20-85 atm), T-shaped micromixer $(1000 \mu \mathrm{m}$ i.d.), residence time unit (1000 $\mu \mathrm{m}$ i.d. length: $8 \mathrm{~m}$ for entries $1-3,18 \mathrm{~m}$ for entries $4-7)$. bYields were determined by GC analysis using decane as an internal standard.

flow system, we then carried out a three-component coupling reaction comprised of 1-iodooctane (9), CO, and methyl vinyl ketone in the presence of tributyltin hydride [24], which also worked well to give 2,5-tridecandione (10) in $78 \%$ yield (entry 5).
Since tris(trimethylsilyl)silane (TTMSS) delivers a hydrogen atom to a carbon-centered radical at a slower rate than tributyltin hydride [25], carbonylation reactions with TTMSS can be carried out at lower CO pressure without being plagued by the premature reduction of the key radical. Hence, we anti- 
cipated that the combination of low pressure CO/V-65 could be successfully applied to the TTMSS-mediated three component carbonylative-coupling reaction of 1-iodooctane (9) [26,27] in a microflow system using methyl vinyl ketone and acrylonitrile as acyl radical traps (entries 6 and 7 ). Gratifyingly, in both cases, good yields of the three-component coupling products were formed by using reduced $\mathrm{CO}$ pressure.

\section{Conclusion}

We have developed a facile platform to conduct radical carbonylation under $\mathrm{CO}$ pressure in a flow system comprised of a T-shaped mixer and a tabular residence time unit. Using V-65 as a radical initiator, we were able to carry out typical tin- or silicon-based radical carbonylation reactions leading to aldehydes, unsymmetrical ketones, and a lactam, in a continuous microflow system.

\section{Experimental}

Typical procedure for radical carbonylation in a microflow system. The radical formylation of 1-bromododecane (1). 1-Bromododecane (1, $1 \mathrm{mmol}, 249.5 \mathrm{mg}), \mathrm{V}-65$ (0.1 mmol, $24.8 \mathrm{mg}), \mathrm{Bu}_{3} \mathrm{SnH}(1.2 \mathrm{mmol}, 352.9 \mathrm{mg})$, and decane $(59 \mathrm{mg})$ as an internal standard were dissolved in toluene $(50 \mathrm{~mL})$. The toluene solution was placed in a syringe $(17 \mathrm{~mL})$, which was then attached to a syringe pump. The system was pressurized with $\mathrm{CO}(83 \mathrm{~atm})$ by means of the pressure control valve. The flow rate of $\mathrm{CO}$ was controlled at $0.14 \mathrm{~mL} / \mathrm{min}$ by the mass flow controller. The toluene solution was introduced at a flow rate of $0.37 \mathrm{~mL} / \mathrm{min}$, then was mixed with $\mathrm{CO}$ in the T-shaped micromixer (i.d. $=1000 \mu \mathrm{m}$ ). The reaction was then fed into the residence time unit, which was immersed in an oil bath and heated at $80{ }^{\circ} \mathrm{C}$. The time needed for the reaction mixture to travel through the residence time unit was expressed as the residence time (12 $\mathrm{min})$. The mixture of products was collected at the outlet. The initial effluent exiting the microflow reactor was discarded (ca. $20 \mathrm{~min}$ ) until a stable gas-liquid mixing was achieved, and the following portion was collected for a $10 \mathrm{~min}$ period. The yield was determined by GC analysis, and the product was identified by comparison of ${ }^{1} \mathrm{H}$ NMR spectrum and a retention time for $\mathrm{GC}$ analysis with those of authentic sample.

\section{Acknowledgments}

We thank JSPS/MEXT Japan and MCPT/NEDO for their financial support of this work.

\section{References}

1. Wirth, T. Microreactors in Organic Synthesis and Catalysis; Wiley-VCH: Weinheim, 2008. doi:10.1002/9783527622856

2. Hessel, V.; Renken, A.; Schouten, J. C.; Yoshida, J., Eds. Micro Process Engineering; Wiley-VCH: Verlag, 2009
3. Jas, G.; Kirschning, A. Chem.-Eur. J. 2003, 9, 5708-5723. doi:10.1002/chem.200305212

4. Fukuyama, T.; Rahman, M. T.; Sato, M.; Ryu, I. Synlett 2008, 151-163. doi:10.1055/s-2007-1000884

5. Fukuyama, T.; Shinmen, M.; Nishitani, S.; Sato, M.; Ryu, I. Org. Lett. 2002, 4, 1691-1694. doi:10.1021/ol0257732

6. Sugimoto, A.; Fukuyama, T.; Sumino, Y.; Takagi, M.; Ryu, I. Tetrahedron 2009, 65, 1593-1598. doi:10.1016/j.tet.2008.12.063

7. Usutani, H.; Tomida, Y.; Nagaki, A.; Okamoto, H.; Nokami, T.; Yoshida, J. J. Am. Chem. Soc. 2007, 129, 3046-3047. doi:10.1021/ja068330s

8. Sahoo, R. H.; Kralj, J. G.; Jensen, K. F. Angew. Chem., Int. Ed. 2007, 46, 5704-5708. doi:10.1002/anie.200701434

9. Tanaka, K.; Motomatsu, S.; Koyama, K.; Tanaka, S.; Fukase, K. Org. Lett. 2007, 9, 299-302. doi:10.1021/ol062777o

10. Carrel, F. R.; Geyer, K.; Codée, J. D. C.; Seeberger, P. H. Org. Lett. 2007, 9, 2285-2288. doi:10.1021/ol0705503

11. Bogdan, A. R.; Mason, B. P.; Sylvester, K. T.; McQuade, D. T. Angew. Chem., Int. Ed. 2007, 46, 1698-1701. doi:10.1002/anie.200603854

12. Fukuyama, T.; Kobayashi, M.; Rahman, M. T.; Kamata, N.; Ryu, I. Org. Lett. 2008, 10, 533-536. doi:10.1021/ol702718z

13. Odedra, A.; Geyer, K.; Gustafsson, T.; Gilmou, R.; Seeberger, P. H. Chem. Commun. 2008, 3025-3027. doi:10.1039/b803715a

14. Ryu, I. Chem. Soc. Rev. 2001, 30, 16-25. doi:10.1039/a904591k

15. Ryu, I.; Chatgilialoglu, C.; Crich, D.; Komatsu, M. Chem. Rev. 1999, 99, 1991-2069. doi:10.1021/cr9601425

16. Ryu, I.; Sonoda, N. Angew. Chem., Int. Ed. 1996, 35, 1050-1066. doi:10.1002/anie.199610501

17. Ryu, I.; Sonoda, N.; Curran, D. P. Chem. Rev. 1996, 96, 177-194. doi:10.1021/cr9400626

18. Rahman, M. T.; Fukuyama, T.; Kamata, N.; Sato, M.; Ryu, I. Chem. Commun. 2006, 2236-2238. doi:10.1039/b600970k

19. Miller, P. W.; Long, N. J.; de Mello, A. J.; Vilar, R.; Gee, A.; Passchier, J. Chem. Commun. 2006, 546-548. doi:10.1039/b515710b

20. Murphy, E. R.; Martinelli, J. R.; Zaborenko, N.; Buchwald, S. L.; Jensen, K. F. Angew. Chem., Int. Ed. 2007, 46, 1734-1737. doi:10.1002/anie.200604175

21. Ryu, I.; Kusano, K.; Ogawa, A.; Kambe, N.; Sonoda, N. J. Am. Chem. Soc. 1990, 112, 1295-1297. doi:10.1021/ja00159a088

22. Ryu, I.; Miyazato, H.; Kuriyama, H.; Matsu, K.; Tojino, M.; Fukuyama, T.; Minakata, S.; Komatsu, M. J. Am. Chem. Soc. 2003, 125, 5632-5633. doi:10.1021/ja034896u

23. Tojino, M.; Otsuka, N.; Fukuyama, T.; Matsubara, H.; Schiesser, C. H.; Kuriyama, H.; Miyazato, H.; Minakata, S.; Komatsu, M.; Ryu, I. Org. Biomol. Chem. 2003, 1, 4262-4267. doi:10.1039/b309944j

24. Ryu, I.; Kusano, K.; Yamazaki, H.; Sonoda, N. J. Org. Chem. 1991, 56, 5003-5005. doi:10.1021/jo00017a001

25. Chatgilialoglu, C. Organosilanes in Radical Chemistry; John Wiley \& Sons Ltd.: Chichester, 2004. doi:10.1002/0470024755

26. Ryu, I.; Hasegawa, M.; Kurihara, A.; Ogawa, A.; Tsunoi, S.; Sonoda, A. Synlett 1993, 143-145. doi:10.1055/s-1993-22381

27. Kishimoto, Y.; Ikariya, T. J. Org. Chem. 2000, 65, 7656-7659. doi:10.1021/jo001135q 


\section{License and Terms}

This is an Open Access article under the terms of the Creative Commons Attribution License

(http://creativecommons.org/licenses/by/2.0), which permits unrestricted use, distribution, and reproduction in any medium, provided the original work is properly cited.

The license is subject to the Beilstein Journal of Organic Chemistry terms and conditions:

(http://www.beilstein-journals.org/bjoc)

The definitive version of this article is the electronic one which can be found at:

doi:10.3762/bjoc.5.34 